\title{
Deep Eutectic Solvents as Novel and Effective Extraction Media for Quantitative Determination of Ochratoxin A in Wheat and Derived Products
}

\author{
Luca Piemontese ${ }^{1,2}$, Filippo Maria Perna ${ }^{2}$, Antonio Logrieco ${ }^{1}$, Vito Capriati ${ }^{2, *}$ \\ and Michele Solfrizzo ${ }^{1, *}$ \\ 1 Consiglio Nazionale delle Ricerche, Istituto di Scienze delle Produzioni Alimentari, \\ Via G. Amendola 122/O, I-70126 Bari, Italy; luca.piemontese@uniba.it (L.P.); \\ antonio.logrieco@ispa.cnr.it (A.L.) \\ 2 Dipartimento di Farmacia-Scienze del Farmaco, Università degli Studi di Bari "Aldo Moro", \\ Consorzio C.I.N.M.P.I.S., Via E. Orabona 4, I-70125 Bari, Italy; filippo.perna@uniba.it \\ * Correspondence: vito.capriati@uniba.it (V.C.); michele.solfrizzo@ispa.cnr.it (M.S.); \\ Tel.: +39-080-5442174 (V.C.); +39-080-5929367 (M.S.)
}

Academic Editors: Hua Zhao and Derek J. McPhee

Received: 11 November 2016; Accepted: 10 January 2017; Published: 12 January 2017

\begin{abstract}
An unprecedented, environmentally friendly, and faster method for the determination of Ochratoxin A (OTA) (a mycotoxin produced by several species of Aspergillus and Penicillium and largely widespread in nature, in wheat and derived products) has, for the first time, been set up and validated using choline chloride $(\mathrm{ChCl}$ )-based deep eutectic solvents (DESs) (e.g., $\mathrm{ChCl}$ /glycerol $(1: 2)$ and $\mathrm{ChCl} /$ urea (1:2) up to $40 \%(w / w)$ water) as privileged, green, and biodegradable extraction solvents. This also reduces worker exposure to toxic chemicals. Results are comparable to those obtained using conventional, hazardous and volatile organic solvents (VOCs) typical of the standard and official methods. OTA recovery from spiked durum wheat samples, in particular, was to up to $89 \%$ versus $93 \%$ using the traditional acetonitrile-water mixture with a repeatability of the results $\left(\mathrm{RSD}_{\mathrm{r}}\right)$ of $7 \%$. Compatibility of the DES mixture with the antibodies of the immunoaffinity column was excellent as it was able to retain up to $96 \%$ of the OTA. Recovery and repeatability for durum wheat, bread crumbs, and biscuits proved to be within the specifications required by the current European Commission (EC) regulation. Good results in terms of accuracy and precision were achieved with mean recoveries between 70\% (durum wheat) and $88 \%$ (bread crumbs) and an RSD $_{\mathrm{r}}$ between $2 \%$ (biscuits) and $7 \%$ (bread).
\end{abstract}

Keywords: deep eutectic solvents; Ochratoxin A; food chemistry; analytical method; green solvents

\section{Introduction}

Ochratoxin A (OTA) (Figure 1) is a mycotoxin produced by several species of Aspergillus and Penicillium, and has been detected in wheat and other cereals (the main source of human exposure to OTA), coffee beans, beans, pulses, dried fruit and wine all over the world [1]. This toxin possesses carcinogenic, nephrotoxic, teratogenic, immunotoxic and neurotoxic properties, and is potentially carcinogenic to humans (Group 2B) [1]. To protect human health, a tolerable weekly intake (TWI) of $120 \mathrm{ng} / \mathrm{kg}$ b.w. of OTA was established by the European Food Safety Authority (EFSA) [1]. 


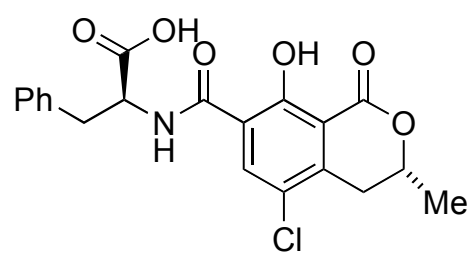

Figure 1. Molecular structure of Ochratoxin A.

The maximum levels of OTA in 13 different categories of foodstuffs marketed in the European Union (EU) are regulated by legislation [2], but new sources of human exposure to this mycotoxin are continuously reported [3,4]. One of the main issues related to the Official Method 2000.3 of the Association of Official Analytical Chemists [5] and the CEN-EN 1432:2009 [6] standard method of the European Committee for Standardization for OTA determination in foodstuffs is the use of acetonitrile, a hazardous and volatile organic solvent (VOC), for the extraction process. In these methods the sample extract in acetonitrile:water $(60: 40 \mathrm{v} / \mathrm{v})$ is diluted $(1: 11 \mathrm{v} / \mathrm{v})$ with an aqueous phosphate buffer solution (PBS) before the purification/concentration on the immunoaffinity (IMA) column. Dilution is necessary because the antibodies of the IMA columns do not tolerate a percentage of VOC $>5 \%-10 \%$ in the loading solution.

Deep eutectic solvents (DESs) represent a nascent class of formidable, unconventional fluids generally obtained by mixing quaternary ammonium salts with metal salts or hydrogen bond donors. These coalitions of safe and inexpensive components, typically coming from renewal sources (e.g., choline chloride ( $\mathrm{ChCl})$, urea, glycerol (Gly), polyalcohols, etc.), are able to undergo self-association so as to form a eutectic mixture with a significant reduction of the freezing point, which exhibits unusual solvent properties [7-9]. Thanks to their shallow environmental and economic impact (non-flammability, biodegradability, ease of preparation with no further purification, low volatility, very low or non-toxicity, recyclability), DESs are gathering considerable and increasing interest as front-runners for "green" solvents, and are progressively substituting conventional VOCs in several fields of science and technology [10-18]. When the compounds that constitute DESs are primary metabolites (e.g., amino acids, carbohydrates, organic acids, etc.), DESs are usually called NADES (natural deep eutectic solvents) [19]. According to a recent, fascinating theory developed by Verpoorte and co-workers, NADES could play a major role in the biochemistry of cells and organisms as well as in storage and transport of poorly water-soluble compounds as a third type of solvent, besides water and lipids [20]. A range of breakthrough applications have in particular been recently established in the fields of organocatalysis [21-24], organometallic chemistry [25-30], metal-catalyzed reactions [31-36], biotransformations [37-39], and solar technology [40]. Though excellent progress has also been made in extraction and separation processes using DESs and NADES (e.g., selective isolation and recovery of metals, environmental pollutants and target compounds from natural products, purification of fuels, azeotrope breaking, etc.) [41-50], there is still no report on their use for the qualitative and quantitative determination of important food contaminants. The present study describes an unprecedented analytical method for the determination of OTA in wheat and derived products using, for the first time, DESs as selective and environmentally friendly extraction media. The values of recoveries and the repeatability of results $\left(\mathrm{RSD}_{\mathrm{r}}\right)$ comply with the performance criteria for OTA set out in the EU Regulation [51], and are comparable to those obtained with the CEN-EN 1432:2009 standard method [6].

\section{Results and Discussion}

Preliminary experiments were performed to check the extraction efficiency of binary and ternary ChCl-based eutectic mixtures (i.e., $\mathrm{ChCl} / \mathrm{Gly}(1: 2 \mathrm{~mol} / \mathrm{mol})(\mathrm{DES} \mathrm{A})$ and $\mathrm{ChCl} /$ urea $(1: 2 \mathrm{~mol} / \mathrm{mol})$ $+20 \%(w / w)$ water (DES B)). Ground wheat samples $(4 \mathrm{~g})$ were spiked with OTA at a high level $(203 \mu \mathrm{g} / \mathrm{kg})$ and extracted with DES A or DES B. The sample extracts were diluted $(1: 1 v / v)$ with 
water, filtered and analyzed by HPLC with a fluorescence detector (HPLC-FLD) without cleanup of the extract. For comparison, spiked wheat samples were extracted with acetonitrile/water 60:40 (v/v), the solvent mixture used in the official [5] and standard [6] methods. The sample extract was diluted with water and analyzed by HPLC-FLD. The two DESs proved to be both effective in the extraction and solubilization of OTA, giving a recovery of up to $89 \%\left(\mathrm{RSD}_{\mathrm{r}}=7 \%\right)$, which is quite close to the recovery observed using the traditional acetonitrile-water mixture (93\%) (Table 1). Further extraction experiments conducted at a higher temperature $\left(40^{\circ} \mathrm{C}\right)$ and using sonication did not improve either recovery rates $(83 \%)$ or the repeatability of results $\left(\mathrm{RSD}_{\mathrm{r}}=6 \%\right)$.

Table 1. Extraction of OTA with VOC and DES mixtures from durum wheat samples spiked at $203 \mu \mathrm{g} / \mathrm{kg}(n=3)$.

\begin{tabular}{ccccc}
\hline Extraction Medium & OTA $(\boldsymbol{\mu g} / \mathbf{k g})$ & SD $^{\mathbf{a}}(\boldsymbol{\mu g} / \mathbf{k g})$ & RSD $_{\mathbf{r}} \mathbf{b}_{(\%)}$ & Mean Recovery $(\%)^{\text {(\%) }}$ \\
\hline VOC $^{\mathrm{c}}$ & 189 & 2 & 1 & 93 \\
$\mathrm{DES} \mathrm{A}^{\mathrm{d}}$ & 164 & 20 & 12 & 81 \\
DES B $^{\mathrm{e}}$ & 180 & 13 & 7 & 89 \\
\hline
\end{tabular}

${ }^{a}$ SD: standard deviation. ${ }^{b} \mathrm{RSD}_{\mathrm{r}}$ : within laboratory relative standard deviation. ${ }^{\mathrm{c}}$ VOC: acetonitrile/water $(60: 40 \mathrm{v} / \mathrm{v}) .{ }^{\mathrm{d}} \mathrm{DES} \mathrm{A}: \mathrm{ChCl} / \mathrm{Gly}(1: 2 \mathrm{~mol} / \mathrm{mol}) .{ }^{\mathrm{e}} \mathrm{DES} \mathrm{B}: \mathrm{ChCl} /$ urea $(1: 2 \mathrm{~mol} / \mathrm{mol})+20 \%(\mathrm{w} / \mathrm{w})$ water.

The compatibility of DES mixtures with the antibodies of the IMA column, capable of retaining up to $100 \mathrm{ng}$ OTA, was then tested. Sixteen IMA columns were loaded with a volume (from 0.125 to $5 \mathrm{~mL}$, in duplicate, equivalent to $4.5-180 \mathrm{ng}$ OTA) of a durum wheat extract in DES B spiked at an OTA concentration of $36 \mathrm{ng} / \mathrm{mL}$. After washing the columns with water (discarded), OTA was eluted from the columns with methanol which was analyzed by HPLC/FLD to check the capability of the columns to retain OTA loaded with increasing volumes of DES extracts and OTA amounts. As shown in Figure 2, IMA columns proved to be able to retain $67 \%-96 \%$ of OTA loaded at a toxin amount below the maximum capacity of the column (100 ng) and 61\% (110 ng) at $180 \mathrm{ng}$ of loaded OTA. It is noteworthy that the sample extract in DES (up to $5 \mathrm{~mL}$ ) can be directly loaded onto the IMA column without any dilution with PBS. Instead, in the AOAC official and CEN-EN standard methods the sample extract $(4 \mathrm{~mL})$ in acetonitrile:water $(60: 40 \mathrm{v} / \mathrm{v})$ must be diluted with $44 \mathrm{~mL}$ of PBS prior to loading onto the IMA column. Therefore, the purification/concentration step is significantly shortened by passing through the column's $5 \mathrm{~mL}$ of extract instead of $48 \mathrm{~mL}$.

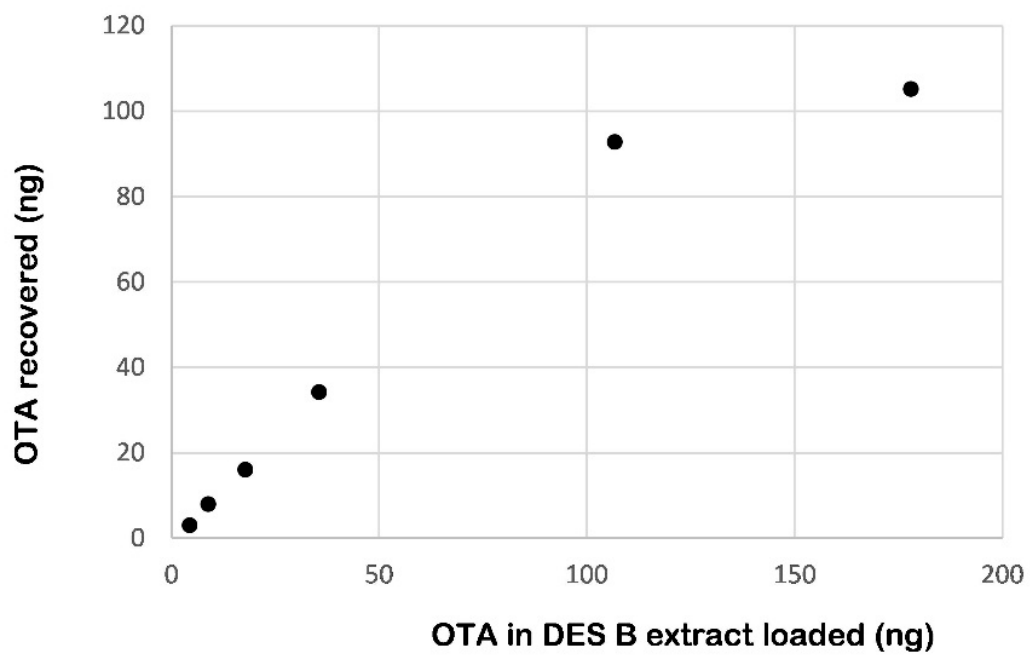

Figure 2. Capability of OchraTest $\mathrm{WB}^{\circledR} \mathrm{IMA}$ column to retain OTA from DES B $(\mathrm{ChCl} /$ urea $(1: 2 \mathrm{~mol} / \mathrm{mol})$ $+20 \%(w / w)$ water) extract of milled durum wheat. 
The extraction efficiency of the whole procedure was then tested on wheat samples spiked at a lower level of OTA $(5 \mu \mathrm{g} / \mathrm{kg})$ and extracted in duplicate with the $\mathrm{ChCl} / \mathrm{urea}(1: 2 \mathrm{~mol} / \mathrm{mol})$ eutectic mixture, increasing the percentage of water from $20 \%$ to $40 \%(w / w)$. Sample extracts were purified/concentrated with IMA columns and analyzed by HPLC-FLD. Acceptable and comparable mean recoveries $(72 \%-74 \%)$ were obtained by using the three extraction mixtures (Figure 3 ). Therefore, $\mathrm{ChCl} /$ urea $+40 \%(w / w)$ water (DES C) was selected as the privileged eutectic mixture for further extraction experiments because of its very low viscosity which facilitates the elution of sample extraction through the IMA column.

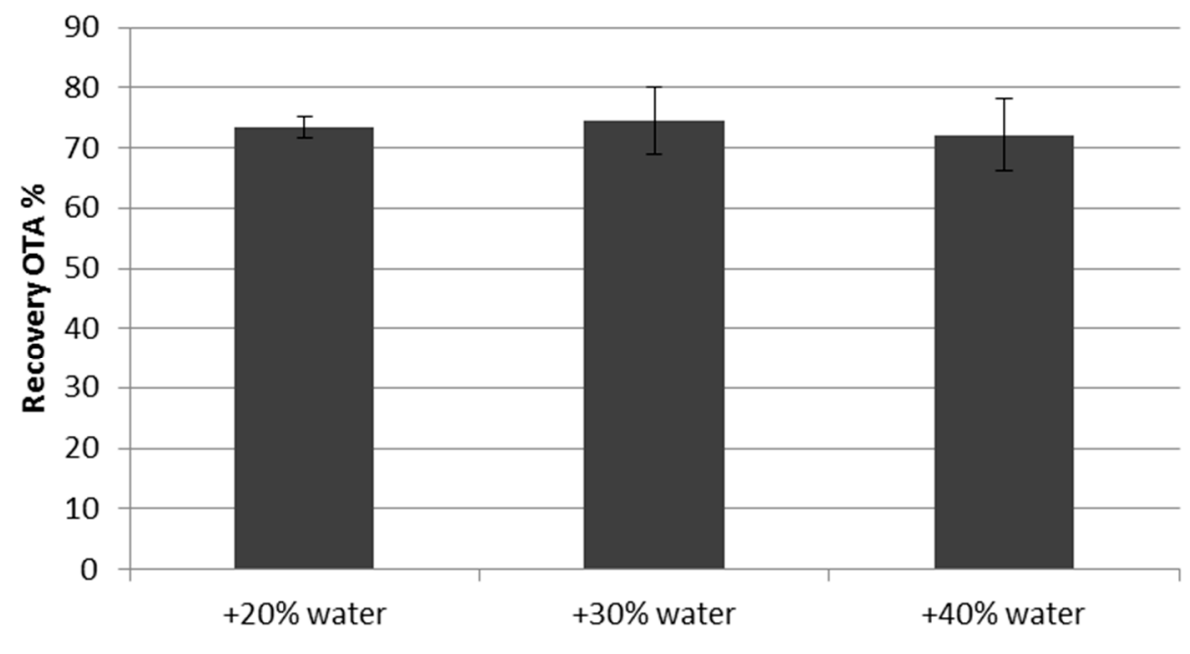

$\%$ water added with DES (choline chloride/urea 1:2 $\mathrm{mol} / \mathrm{mol}$ )

Figure 3. Percentage recoveries of OTA from spiked wheat using DES containing increasing percentages of water as extraction media.

The performances of the new method were tested on durum wheat and three derived products (bread crumbs, biscuits, and bran) spiked in quintuplicate with OTA at $3 \mu \mathrm{g} / \mathrm{kg}$, the EU limit for cereal-based products. Four grams of milled samples were extracted with $20 \mathrm{~mL}$ of DES C by shaking $(1 \mathrm{~h}$, room temperature). After centrifugation and filtration through a filter paper, $5 \mathrm{~mL}$ of filtrate (equivalent to $1 \mathrm{~g}$ of matrix) was passed through an OchraTest $\mathrm{WB}^{\circledR}$ IMA column at a flow rate of about 1 drop/s. The column was washed with $1 \mathrm{~mL}$ of water at a speed of one to two drops/s and the two eluates were discarded. OTA was eluted from the column by passing $1+0.5 \mathrm{~mL}$ of methanol which was collected in a vial, dried under a nitrogen stream at about $50{ }^{\circ} \mathrm{C}$ and reconstituted with $500 \mu \mathrm{L}$ of the HPLC mobile phase. One hundred microliters of purified extract, corresponding to $0.2 \mathrm{~g}$ of sample, were analyzed by HPLC/FLD (see Materials and Methods Section).

For three out of the four matrices, good results were achieved in terms of accuracy and precision with mean recoveries between $70 \%$ (durum wheat) and $88 \%$ (bread crumbs) and $\mathrm{RSD}_{\mathrm{r}}$ values between $2 \%$ (biscuits) and 7\% (bread) (Table 2). Low mean recovery was obtained for bran (42\%), which is outside the criteria established in the EC Regulation, although the value of the $\operatorname{RSD}_{\mathrm{r}}(11 \%)$ is acceptable [51]. A possible explanation for this low recovery could be due to the high fiber content of bran which considerably reduces the penetration of DES into the matrix, there by limiting OTA extractability. The values of the limit of detection (LOD) and limit of quantitation (LOQ) were calculated as signal-to-noise ratios of 3:1 and 9:1 and were $0.09 \mu \mathrm{g} / \mathrm{kg}$ and $0.27 \mu \mathrm{g} / \mathrm{kg}$, respectively. These results comply with the method criteria proposed by codex committee on methods of analysis and sampling (CCMAS) [52], i.e., maximum limit (ML) $<100 \mu \mathrm{g} / \mathrm{kg}, \mathrm{LOD} \leq \mathrm{ML} \times 1 / 5$ and $\mathrm{LOQ}<\mathrm{ML} \times 2 / 5$. For a ML of $3 \mu \mathrm{g} / \mathrm{kg}$, the LOD and LOQ should be $<0.6$ and $<1.2 \mu \mathrm{g} / \mathrm{kg}$, respectively. In our case, the values of LOD and LOQ were seven and four times below these limits, respectively. To check the linearity and range of applicability of the new method, further recovery experiments were performed 
on durum wheat spiked in triplicate at seven different OTA levels, ranging between 1 and $100 \mu \mathrm{g} / \mathrm{kg}$. The overall mean recovery in the range of 3-100 $\mu \mathrm{g} / \mathrm{kg}$ was $70 \%\left(\mathrm{RSD}_{\mathrm{r}}=7 \%\right)$, whereas at $1 \mu \mathrm{g} / \mathrm{kg}$ of the mean recovery was $64 \%\left(\operatorname{RSD}_{\mathrm{r}}=5 \%\right)$. For comparison, the above spiked wheat samples were re-analyzed (seven different levels in triplicate) using the CEN-EN 14132:2009 standard method which uses acetonitrile:water $(60: 40 \mathrm{v} / \mathrm{v})$ as the extraction solvent. A very good correlation was obtained $\left(\mathrm{R}^{2}=0.9948\right)$ comparing the results obtained with the two methods (see Supplementary Materials). Recoveries and RSD obtained with the CEN-EN standard method ranged between 91\%-100\% and $2 \%-10 \%$, respectively.

Table 2. Determination of OTA in four cereal-based matrices spiked at $3 \mu \mathrm{g} / \mathrm{kg}(n=5)$ by using DES $\mathrm{C}^{\mathrm{a}}$ as the extraction medium.

\begin{tabular}{cccc}
\hline Matrix & OTA $(\boldsymbol{\mu g} / \mathbf{k g})$ & RSD $_{\mathbf{r}} \mathbf{( \% )}$ & Mean Recovery (\%) \\
\hline Durum wheat & $2.11 \pm 0.11$ & 5 & 70 \\
Bread crumbs & $2.65 \pm 0.17$ & 7 & 88 \\
Biscuits & $2.25 \pm 0.04$ & 2 & 75 \\
Bran & $1.25 \pm 0.14$ & 11 & 42 \\
\hline
\end{tabular}

${ }^{\mathrm{a}}$ DES C: $\mathrm{ChCl} /$ urea $(1: 2 \mathrm{~mol} / \mathrm{mol})+40 \%(\mathrm{w} / \mathrm{w})$ water.

\section{Materials and Methods}

\subsection{Preparation of DESs}

The eutectic mixtures of choline chloride/glycerol $(1: 2 \mathrm{~mol} / \mathrm{mol})$ and choline chloride/urea $(1: 2 \mathrm{~mol} / \mathrm{mol})$ were prepared by heating under stirring up to $60{ }^{\circ} \mathrm{C}$ for $10 \mathrm{~min}$ the corresponding individual components until a clear solution was obtained. Water $(20 \%-40 \%(w / w))$, where required, was then added, and the mixture was further stirred at room temperature for about $30 \mathrm{~min}$.

\subsection{Samples}

Samples of durum wheat and bran originating from Canada were provided by a local importer (Bari, Italy). Commercial samples of bread and biscuits were purchased by local retails (Bari, Italy).

\subsection{Reagents and Materials}

Solid standard of OTA was purchased from Sigma-Aldrich (Milan, Italy). The stock solution $(1 \mathrm{mg} / \mathrm{mL})$ was prepared by weighing $1 \mathrm{mg}$ of the toxin, which was then dissolved in $1 \mathrm{~mL}$ of toluene/acetic acid (99:1, $v / v)$. To assess the exact concentration of the OTA stock solution, an aliquot was evaporated to dryness, redissolved in methanol at concentration of about $10 \mu \mathrm{g} / \mathrm{mL}$, and spectrophotometrically tested $\left(\varepsilon=6330 \mathrm{~cm}^{2} / \mathrm{mmol}\right.$, at $\left.\lambda=332 \mathrm{~nm}\right)$. Standard solutions of OTA for HPLC calibration or spiking purposes were prepared by dissolving adequate amounts of the stock solution, previously evaporated to dryness under nitrogen stream, in the HPLC mobile phase. Acetonitrile, methanol, water (HPLC grade), and glacial acetic acid were purchased from Mallinckrodt Baker (Milan, Italy). Choline chloride, urea, and glycerol were purchased from Alfa Aesar (Karlsruhe, Germany).

\subsection{HPLC Determination of OTA}

The HPLC determination and confirmation of OTA were performed according to the CEN-EN 14132:2009 standard method [6]. The HPLC-FLD analyses were performed with an Agilent 1260 Infinity (Agilent Technologies, Inc., Wilmington, DE, USA), consisting of a binary pump (G1312B), an auto sampler (G1367E) with a $100 \mu \mathrm{L}$ loop, a fluorescence detector (G1321B) fixed at $333 \mathrm{~nm}\left(\lambda_{\text {ex }}\right)$ and $460 \mathrm{~nm}\left(\lambda_{\mathrm{em}}\right)$, a thermostatic oven set at $30^{\circ} \mathrm{C}$ and a software for Microsoft Windows 7 (OpenLAB, CDS, ChemStation Edition). The column used was a $150 \times 4.6 \mathrm{~mm}$ i.d., $5 \mu \mathrm{m}$, Zorbax C18, (Phenomenex, Torrance, CA, USA) with a $3 \mathrm{~mm}$ i.d. and a $0.45 \mu \mathrm{m}$ pore size guard filter (Rheodyne, Cotati, CA, USA). 
The mobile phase was an isocratic mixture of acetonitrile/water/acetic acid (99:99:2, v/v/v) eluted at a flow rate of $1.0 \mathrm{~mL} / \mathrm{min}$.

\section{Conclusions}

In summary, the main advantages of the described method are (a) the use of biodegradable and renewable substances as extraction media of food contaminants in place of hazardous and toxic VOCs (e.g., acetonitrile), which are still massively employed in analytical laboratories; (b) performances (recovery rates and repeatability) acceptable and within the criteria specified by the current EC Regulation n. 401 [51] and CCMAS [52]; (c) data analysis achieved faster and easier since the sample extract can be directly purified on the IMA column without the need for a large dilution with PBS. Moreover, what is remarkable and auspicious for future research in food control is the high compositional flexibility of DESs with the possibility of fine-tuning their physico-chemical properties. Our efforts are currently focused on the developments and validation of new, faster, reliable and environmentally friendly analytical methods for the quantitative determination of other important contaminants in food commodities using custom-tailored DES mixtures, and results will be reported in due course.

Supplementary Materials: Supplementary materials can be accessed at: http:/ /www.mdpi.com/1420-3049/22/ $1 / 121 /$ s1.

Acknowledgments: This work was financially supported by the CNR Institute of Sciences of Food Production and University of Bari within the framework of the following Projects: Mycokey-Horizon 2020 (Grant Agreement: 678781). L.P. would like to acknowledge Fondo di Sviluppo e Coesione 2007-2013, APQ Ricerca Regione Puglia "Programma regionale a sostegno della specializzazione intelligente e della sostenibilità sociale ed ambientale-FutureInResearch"-Project ID:I2PCTF6. F.M.P. and V.C. thank the Interuniversities Consortium C.I.N.M.P.I.S. for partially supporting this research project.

Author Contributions: L.P. carried out the experimental work and wrote the first draft of the paper; F.M.P. and A.L. analyzed data and participated in the discussion of the obtained results; M.S. contributed reagents/materials/analysis tools; V.C. and M.S. conceived and designed the experiments, wrote and revised the final draft of the paper.

Conflicts of Interest: The authors declare no conflict of interest.

\section{References}

1. European Food Safety Authority (EFSA). Opinion of the scientific panel on contaminants in the food chain on a request from the commission related to ochratoxin A in food. EFSA J. 2006, 365, 1-56.

2. European Commission. Commission Regulation (EC) No. 1881/2006 of 19 December 2006 Setting Maximum Levels for Certain Contaminants in Foodstuffs. Off. J. Eur. Union. 2006, 364, 5-24 and Successive Amendments. Available online: http:/ /eur-lex.europa.eu/legal-content/en/ALL/?uri=CELEX:32006R1881 (accessed on 11 January 2017).

3. Solfrizzo, M.; Piemontese, L.; Gambacorta, L.; Zivoli, R.; Longobardi, F. Food Coloring Agents and Plant Food Supplements Derived from Vitis vinifera: A New Source of Human Exposure to Ochratoxin A. J. Agric. Food Chem. 2015, 63, 3609-3614. [CrossRef] [PubMed]

4. Piemontese, L. Plant Food Supplements with Antioxidant Properties for the Treatment of Chronic and Neurodegenerative Diseases: Benefits or Risks? J. Diet. Suppl. 2016. [CrossRef] [PubMed]

5. Entwisle, A.C.; Williams, A.C.; Mann, P.J.; Slack, P.T.; Gilbert, J. Liquid chromatographic method with immunoaffinity column cleanup for determination of ochratoxin A in barley: Collaborative study. J. AOAC Int. 2000, 83, 1377-1383. [PubMed]

6. European Committee for Standardization (CEN). Foodstuffs-Determination of Ochratoxin A in Barley and Roasted Coffee: HPLC Method with Immunoaffinity Column Clean-Up; EN 14132; CEN: Brussels, Belgium, 2009; p. 16.

7. Abbott, A.P.; Capper, G.; Davies, D.L.; Rasheed, R.K.; Tambyrajah, V. Novel solvent properties of choline chloride/urea mixtures. Chem. Commun. 2003, 70-71. [CrossRef] 
8. Abbott, A.P.; Boothby, D.; Capper, G.; Davies, D.L.; Rasheed, R.K. Deep Eutectic Solvents formed between choline chloride and carboxylic acids: Versatile alternatives to ionic liquids. J. Am. Chem. Soc. 2004, 126, 9142-9147. [CrossRef] [PubMed]

9. Abbott, A.P.; Barron, J.C.; Ryder, K.S.; Wilson, D. Eutectic-based ionic liquids with metal-containing anions and cations. Chem. Eur. J. 2007, 13, 6495-6501. [CrossRef] [PubMed]

10. Ruß, C.; König, B. Low melting mixtures in organic synthesis-An alternative to ionic liquids? Green Chem. 2012, 14, 2969-2982. [CrossRef]

11. Zhang, Q.; De Oliveira Vigier, K.; Royer, S.; Jérôme, F. Deep eutectic solvents: Syntheses, properties and applications. Chem. Soc. Rev. 2012, 41, 7108-7146. [CrossRef] [PubMed]

12. Gu, Y.; Jérôme, F. Bio-based solvents: An emerging generation of fluids for the design of eco-efficient processes in catalysis and organic chemistry. Chem. Soc. Rev. 2013, 42, 9550-9570. [CrossRef] [PubMed]

13. Francisco, M.; van den Bruinhorst, A.; Kroon, M.C. Low-Transition-Temperature Mixtures (LTTMs): A New Generation of Designer Solvents. Angew. Chem. Int. Ed. 2013, 52, 3074-3085. [CrossRef] [PubMed]

14. Smith, E.L.; Abbott, A.P.; Ryder, K.S. Deep Eutectic Solvents (DESs) and Their Applications. Chem. Rev. 2014, 114, 11060-11082. [CrossRef] [PubMed]

15. Liu, P.; Hao, J.-W.; Mo, L.-P.; Zhang, Z.-H. Recent advances in the application of deep eutectic solvents as sustainable media as well as catalysts in organic reactions. RSC Adv. 2015, 5, 48675-48704. [CrossRef]

16. Alonso, D.A.; Baeza, A.; Chinchilla, R.; Guillena, G.; Pastor, I.M.; Ramón, D.J. Deep Eutectic Solvents: The Organic Reaction Medium of the Century. Eur. J. Org. Chem. 2016, 612-632. [CrossRef]

17. Carriazo, D.; Serrano, M.C.; Gutiérrez, M.C.; Ferrer, M.L.; del Monte, F. Deep-eutectic solvents playing multiple roles in the synthesis of polymers and related materials. Chem. Soc. Rev. 2012, 41, 4996-5014. [CrossRef] [PubMed]

18. Del Monte, F.; Carriazo, D.; Serrano, M.C.; Gutiérrez, M.C.; Ferrer, M.L. Deep eutectic solvents in polymerizations: A greener alternative to conventional syntheses. ChemSusChem 2014, 7, 999-1009. [CrossRef] [PubMed]

19. Paiva, A.; Craveiro, R.; Aroso, I.; Martins, M.; Reis, R.L.; Duarte, A.R.C. Natural Deep Eutectic Solvents-Solvents for the 21st Century. ACS Sustainable Chem. Eng. 2014, 2, 1063-1071. [CrossRef]

20. Choi, Y.H.; van Spronsen, J.; Dai, Y.; Verberne, M.; Hollmann, F.; Arends, I.W.C.E.; Witkamp, G.-J.; Verpoorte, R. Are Natural Deep Eutectic Solvents the Missing Link in Understanding Cellular Metabolism and Physiology? Plant Physiol. 2011, 156, 1701-1705. [CrossRef] [PubMed]

21. Muller, C.R.; Meiners, I.; Domínguez de María, P. Highly enantioselective tandem enzyme-organocatalyst crossed aldol reactions with acetaldehyde in deep-eutectic-solvents. RSC Adv. 2014, 4, 46097-46101. [CrossRef]

22. Massolo, E.; Palmieri, S.; Benaglia, M.; Capriati, V.; Perna, F.M. Stereoselective organocatalysed reactions in deep eutectic solvents: Highly tunable and biorenewable reaction media for sustainable organic synthesis. Green Chem. 2016, 18, 792-797. [CrossRef]

23. Martínez, R.; Berbegal, L.; Guillena, G.; Ramón, D.J. Bio-renewable enantioselective aldol reaction in natural deep eutectic solvents. Green Chem. 2016, 18, 1724-1730. [CrossRef]

24. Brenna, D.; Massolo, E.; Puglisi, A.; Rossi, S.; Celentano, G.; Benaglia, M.; Capriati, V. Towards the development of continuous, organocatalytic, and stereoselective reactions in deep eutectic solvents. Beilstein J. Org. Chem. 2016, 12, 2620-2626. [CrossRef]

25. Mallardo, V.; Rizzi, R.; Sassone, F.C.; Mansueto, R.; Perna, F.M.; Salomone, A.; Capriati, V. Regioselective desymmetrization of diaryltetrahydrofurans via directed ortho-lithiation: An unexpected help from green chemistry. Chem. Commun. 2014, 50, 8655-8658. [CrossRef] [PubMed]

26. Vidal, C.; García-Álvarez, J.; Hernán-Gómez, A.; Kennedy, A.R.; Hevia, E. Introducing Deep Eutectic Solvents to Polar Organometallic Chemistry: Chemoselective Addition of Organolithium and Grignard Reagents to Ketones in Air. Angew. Chem. Int. Ed. 2014, 53, 5969-5973. [CrossRef] [PubMed]

27. Sassone, F.C.; Perna, F.M.; Salomone, A.; Florio, S.; Capriati, V. Unexpected lateral-lithiation-induced alkylative ring opening of tetrahydrofurans in deep eutectic solvents: Synthesis of functionalised primary alcohols. Chem. Commun. 2015, 51, 9459-9462. [CrossRef] [PubMed]

28. García-Álvarez, J.; Hevia, E.; Capriati, V. Reactivity of Polar Organometallic Compounds in Unconventional Reaction Media: Challenges and Opportunities. Eur. J. Org. Chem. 2015, 6779-6799.

29. García-Álvarez, J. Deep Eutectic Mixtures: Promising Sustainable Solvents for Metal-Catalysed and Metal-Mediated Organic Reactions. Eur. J. Inorg. Chem. 2015, 5147-5157. [CrossRef] 
30. Cicco, L.; Sblendorio, S.; Mansueto, R.; Perna, F.M.; Salomone, A.; Florio, S.; Capriati, V. Water opens the door to organolithiums and Grignard reagents: Exploring and comparing the reactivity of highly polar organometallic compounds in unconventional reaction media towards the synthesis of tetrahydrofurans. Chem. Sci. 2016, 7, 1192-1199. [CrossRef]

31. Rodríguez-Àlvarez, M.J.; Vidal, C.; Díez, J.; García-Álvarez, J. Introducing deep eutectic solvents as biorenewable media for $\mathrm{Au}(\mathrm{I})$-catalysed cycloisomerisation of $\gamma$-alkynoic acids: An unprecedented catalytic system. Chem. Commun. 2014, 50, 12927-12929. [CrossRef] [PubMed]

32. Vidal, C.; Merz, L.; García-Álvarez, J. Deep eutectic solvents: Biorenewable reaction media for Au(I)-catalysed cycloisomerisations and one-pot tandem cycloisomerisation/Diels-Alder reactions. Green Chem. 2015, 17, 3870-3878. [CrossRef]

33. Lu, J.; Li, X.T.; Ma, E.Q.; Mo, L.P.; Zhang, Z.H. Superparamagnetic $\mathrm{CuFeO}_{2}$ Nanoparticles in Deep Eutectic Solvent: An Efficient and Recyclable Catalytic System for the Synthesis of Imidazo[1,2-a]pyridines. ChemCatChem 2014, 6, 2854-2859. [CrossRef]

34. Imperato, G.; Höger, S.; Lenoir, D.; König, B. Low melting sugar-urea-salt mixtures as solvents for organic reactions-Estimation of polarity and use in catalysis. Green Chem. 2006, 8, 1051-1055. [CrossRef]

35. Imperato, G.; Vasold, R.; König, B. Stille reactions with tetraalkylstannanes and phenyltrialkylstannanes in low melting sugar-urea-salt mixtures. Adv. Synth. Catal. 2006, 348, 2243-2247. [CrossRef]

36. Mancuso, R.; Maner, A.; Cicco, L.; Perna, F.M.; Capriati, V.; Gabriele, B. Synthesis of thiophenes in a deep eutectic solvent: Heterocyclodehydration and iodocyclization of 1-mercapto-3-yn-2-ols in a choline chloride/glycerol medium. Tetrahedron 2016, 72, 4239-4244. [CrossRef]

37. Domínguez de María, P. Deep Eutectic Solvents: Promising Solvents and Nonsolvent Solutions for Biocatalysis. In Environmentally Friendly Synthesis Using Ionic Liquids; Dupont, T.I.J., Lozano, P., Mahotra, S.V., Eds.; CRC Press: Boca Raton, FL, USA, 2014; p. 67.

38. Domínguez de María, P.; Hollmann, F. On the (Un)greenness of Biocatalysis: Some Challenging Figures and Some Promising Options. Front. Microbiol. 2015, 6, 1257. [CrossRef] [PubMed]

39. Vitale, P.; Abbinante, V.M.; Perna, F.M.; Salomone, A.; Cardellicchio, C.; Capriati, V. Unveiling the Hidden Performance of Whole Cells in the Asymmetric Bioreduction of Aryl-containing Ketones in Aqueous Deep Eutectic Solvents. Adv. Synth. Cat. 2017, in press. [CrossRef]

40. Boldrini, C.L.; Manfredi, N.; Perna, F.M.; Trifiletti, V.; Capriati, V.; Abbotto, A. Dye-sensitized solar cells using an aqueous choline chloride-based deep eutectic solvent as an effective electrolyte solution. Energy Technol. 2017, in press. [CrossRef]

41. Pena-Pereira, F.; Namieśnik, J. Ionic Liquids and Deep Eutectic Mixtures: Sustainable Solvents for Extraction Processes. ChemSusChem 2014, 7, 1784-1800. [CrossRef] [PubMed]

42. Tang, B.; Zhang, H.; Row, K.H. Application of deep eutectic solvents in the extraction and separation of target compounds from various samples. J. Sep. Sci. 2015, 38, 1053-1064. [CrossRef] [PubMed]

43. Cvjetko Bubalo, M.; Curko, N.; Tomasevic, M.; Kovacevic Ganic, K.; Radojcic Redovnikovic, I. Green extraction of grape skin phenolics by using deep eutectic solvents. Food Chem. 2016, 200, 159-166. [CrossRef] [PubMed]

44. Dai, Y.; van Spronsen, J.; Witkamp, G.-J.; Verpoorte, R.; Choi, Y.H. Natural deep eutectic solvents as new potential media for green technology. Anal. Chimica Acta 2013, 766, 61-68. [CrossRef] [PubMed]

45. Dai, Y.; Witkamp, G.-J.; Verpoorte, R.; Choi, Y.H. Natural deep eutectic solvents as a new extraction media for phenolic metabolites in Carthamus tinctorius L. Anal. Chem. 2013, 85, 6272-6278. [CrossRef] [PubMed]

46. Duan, L.; Dou, L.; Guo, L.; Ping, L.; Liu, E. Comprehensive Evaluation of Deep Eutectic Solvents in Extraction of Bioactive Natural Products. ACS Sustainable Chem. Eng. 2016, 4, 2405-2411. [CrossRef]

47. Paradiso, V.M.; Clemente, A.; Summo, C.; Pasqualone, A.; Caponio, F. Towards green analysis of virgin olive oil phenolic compounds: Extraction by a natural deep eutectic solvent and direct spectrophotometric detection. Food Chem. 2016, 212, 43-47. [CrossRef] [PubMed]

48. Tan, T.; Li, Z.; Mao, X.; Wan, Y.; Qiu, H. Deep eutectic solvent-based liquid-phase microextraction for detection of plant growth regulators in edible vegetable oils. Anal. Methods 2016, 8, 3511-3516. [CrossRef]

49. Tang, B.; Park, H.E.; Row, K.H. Simultaneous extraction of flavonoids from chamaecyparis obtusa using deep eutectic solvents as additives of conventional extractions solvents. J. Chrom. Sci. 2015, 53, 836-840. [CrossRef] [PubMed] 
50. Wei, Z.-F.; Wang, X.-Q.; Peng, X.; Wang, W.; Zhao, C.-J.; Zu, Y.-G.; Fu, Y.-J. Fast and green extraction and separation of main bioactive flavonoids from Radix Scutellariae. Ind. Crops Prod. 2015, 63, 175-181. [CrossRef]

51. European Commission. Commission Regulation (EC) No. 401/2006 of 23 February 2006 laying down the methods of sampling and analysis for the official control of the levels of mycotoxins in foodstuffs. Off. J. Eur. Union. 2006, 70, 12-34.

52. Codex Committee on Methods of Analysis and Sampling (CCMAS). Guidelines for Establishing Methods Criteria for the Identification of Relevant Analytical Methods. Document CX/MAS 09/30/7. Available online: ftp:/ ftp.fao.org/codex/Meetings/CCMAS/ccmas30/ma30_07e.pdf (accessed on 11 January 2017).

Sample Availability: Samples of the compounds are not available.

(C) 2017 by the authors; licensee MDPI, Basel, Switzerland. This article is an open access article distributed under the terms and conditions of the Creative Commons Attribution (CC-BY) license (http:/ / creativecommons.org/licenses/by/4.0/). 